\title{
Erratum to: Effectiveness of Wyoming's Sage-Grouse Core Areas: Influences on Energy Development and Male Lek Attendance
}

\author{
R. Scott Gamo ${ }^{1}$ Jeffrey L. Beck ${ }^{2}$
}

Published online: 11 February 2017

(C) Springer Science+Business Media New York 2017

Erratum to: Environmental Management (2017) 59: 189-203

DOI 10.1007/s00267-016-0789-9

The original version of this article unfortunately contained a mistake in the last sentence of the "Abstract" section.

A correct sentence should read as follows:

The online version of the original article can be found at doi:10.1007/ s00267-016-0789-9.

\section{R. Scott Gamo}

scott.gamo@wyo.gov

1 Wyoming Game and Fish Department and Department of Ecosystem Science and Management, University of Wyoming, Cheyenne, WY 82006, USA

2 Department of Ecosystem Science and Management, University of Wyoming, Laramie, WY 82071, USA
"Our results provide support for the effectiveness of Core Areas in maintaining sage-grouse populations in Wyoming, but also indicate the need for increased conservation actions to improve sage-grouse population response in MZ I".

An "I" after "MZ" has been inserted at the end of the sentence to clarify this statement was intended for application to Western Association of Fish and Wildlife Agencies Management Zone (MZ) I. 